\title{
A decision support model to optimise the operation and maintenance strategies of an offshore renewable energy farm
}

\author{
G. Rinaldi ${ }^{\mathrm{a}, *}$, P.R. Thies ${ }^{\mathrm{a}}$, R. Walker ${ }^{\mathrm{b}}$, L. Johanning ${ }^{\mathrm{a}}$ \\ ${ }^{a}$ College of Engineering, Mathematics and Physical Sciences, University of Exeter, \\ Renewable Energy Group, Cornwall Campus, Penryn TR10 9EZ, United Kingdom \\ ${ }^{\mathrm{b}}$ Mojo Maritime Ltd., Falmouth Business Park, Falmouth, Cornwall, UK \\ *Corresponding Author. E-mail address: G.Rinaldi@exeter.ac.uk
}

\begin{abstract}
In order to accelerate the access into the energy market for ocean renewables, the operation and maintenance (O\&M) costs for these technologies must be reduced. In this paper a reliability-based simulation tool for the optimisation of the management of an offshore renewable energy (ORE) farm is presented. The proposed tool takes into account the reliability data of the simulated devices and estimations on the energy produced to create a series of results in terms of availability and maintainability of the farm. The information produced supports operational and strategic decision making regarding the O\&M for offshore farms. A case study simulating a conceptual tidal energy project, consisting of an array of two tidal turbines located off the north coast of Scotland, is presented to show some of the results achievable with this model. The proposed methodology, although adopted for a tidal farm here, is generally applicable to other kinds of ORE farms.
\end{abstract}

Keywords: Reliability, Availability, Optimisation, Operation and maintenance, Tidal farm

\section{INTRODUCTION}

Offshore renewables hold large potential to contribute to the future renewable energy mix. In order to do so, the costs associated with the deployment of offshore devices need to be strongly reduced and these have to become competitive in respect to other technologies. By definition, O\&M is a combination of all those practical and administrative actions, undertaken in a complex decision-making process, which aim to keep a system, subsystem or single component as efficient and productive as possible during its life cycle. O\&M represents a major share of the total unit energy cost [1], reaching peaks of $30 \%$ of the total cost of a project. Improving O\&M practices and taking design choices that facilitate operational requirements has been therefore indicated as one of the most cost effective approaches for mitigating the financial risks of offshore infrastructures [2]. As can be 
expected, maintaining the considered system in an operating state for a longer time, increasing in this way the availability of the device, means a higher amount of energy produced and consequently greater revenue. However, an increase in availability is obtained through an increase in maintenance efforts and, as a consequence, in maintenance costs [3]. Therefore, selecting the most appropriate maintenance strategy among the many options available is not a straightforward task. Comprehending the dynamics of the farm, taking into account the interactions among different components and all the unexpected events may be extremely challenging. In addition, planning and scheduling of the O\&M activities are extremely dependent on the project and especially the technology considered. For example, the accessibility challenges to take into account for interventions on offshore wind turbines, where wave and wind conditions are fundamental, are different from those to consider for tidal turbines fixed to the sea bed, where tide level and water current are of primary importance. This, or other factors like the failure behaviour and the experience previously acquired with similar devices, have important repercussions on the choice of the proper assets, and as a consequence on the input set to consider for the effective modelling of the farm. Under these circumstances, a number of computational tools have been developed to address this problem and characterize the operational expenditures of an ORE farm, mainly for the offshore wind industry. Most of these models aim to estimate the costs related to the deployment of the farm exploring the different options available and investigating different maintenance regimes. One part of these tools has been developed exclusively as a commercial product, in order to assist farm operators in the monitoring of the O\&M procedures and the control and optimisation of the cost [4-6]. Other models have been proposed in the research literature to contribute to the general knowledge in this area and solve specific targeted problems. Among these, the assessment of the influence of weather forecast uncertainties [7], the applicability of these tools to combined offshore platforms [8], their integration with other techniques [9] and the accurate estimation of the charter rate for the access systems, i.e. vessels and workboats $[10,11]$. But operating conditions can be investigated also in more generic terms. For example these can be referred to device design choices, offshore locations, crew employed or, more in general, maintenance strategies [12]. A thorough review of the models for offshore wind farms belonging to both categories has been provided by Hofmann [13]. Here, these are arranged in different categories depending on their central purpose, i.e. the main aspect or cost driver to characterize.

Thus, the objective of this paper is to provide a novel contribution to the existing range of computational O\&M tools, showing the properties of the developed toolbox and especially how the results obtained with this can be used to support the decision-making process, as well as improve the cost efficiency, of offshore renewables. Focus is given towards the reliability characterization of the device, and the support this can provide in the effective planning and optimization of the power production, with the final aim of reducing the cost of the energy produced.

In the next section the full methodology adopted will be introduced. A case study to show the modelling and optimisation possibilities will be presented in the following section 3. Results will be shown and discussed in section 4 . Future work and optimization proposals will be anticipated in section 5. Finally, conclusions are drawn in the last section 6. 


\section{METHODOLOGY}

This section describes in detail the offshore O\&M tool implemented. Specifics are provided on the input variables required to start the simulations, together with the mechanisms and constraints that regulate their evolution with time. In addition, a full description of the outputs obtained and their use in the strategy planning is presented.

\subsection{THE OFFSHORE O\&M TOOL}

A number of probabilistic evaluation techniques exist to model the systems' reliability and provide an assessment of the maintenance procedures. However, if the modelling of random processes (e.g. unexpected failures) is the objective, Markov chains and Monte Carlo simulation are the most diffused approaches $[13,14]$ due to their degree of flexibility and level of understanding provided. Monte Carlo techniques are a set of non-deterministic mathematical models based on the random sampling of determined quantities. In reliability engineering, Monte Carlo analysis uses reliability data and statistical distributions to define the behaviour of the system over the considered period of time. A time domain approach based on this technique has been adopted to develop the O\&M tool presented in this work. This exploits the generation of random numbers for a sufficient number of times (i.e. for each timestep and each component of the simulated lifecycle) in order to cover all the possibilities and provide unbiased results [15]. The idea of this model is that by exploiting the metocean data (hindcast or synthetic) of the location where the offshore farm is or will be located, together with all the specifications of the projects in terms of devices, vessels and maintenance strategies, it is possible to obtain a series of results that can be analysed in an iterative procedure to characterize the dynamic of the farm and optimise the planning actions. To do so, the model takes into account a large number of inputs, mechanisms and constraints according to the Structured Analysis and Design Technique (SADT) [16], a computational practice used to describe complex systems and which operates on the general basis shown in the diagram in Figure 1 below.

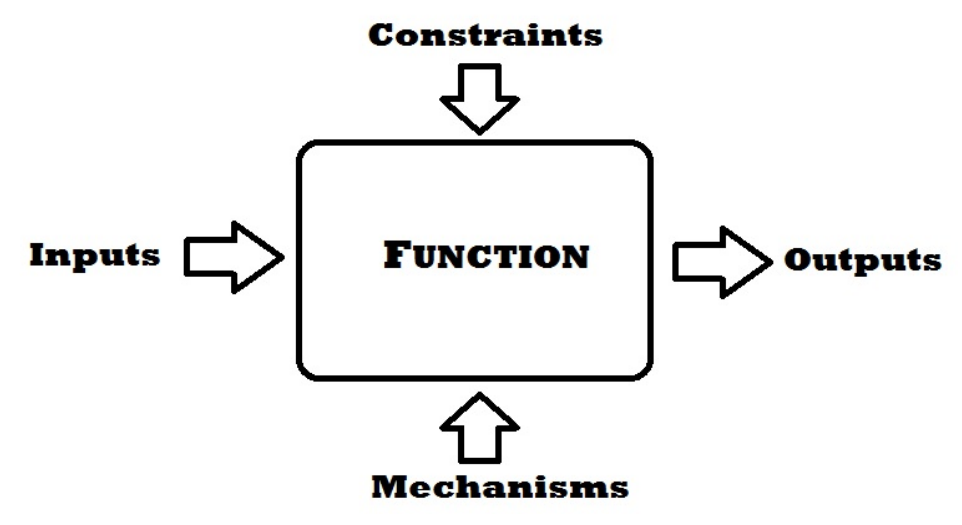

Figure 1. Graphical Representation of SADT.

All the inputs, constraints, mechanisms and outputs considered in this tool will be introduced in the following subsections. 


\subsubsection{Inputs}

The main inputs that the model requires to perform the simulation are:

Number and power rating of the devices. The number of devices that constitute the offshore farm, but not their disposition in the array, must be specified together with the energy converter reference power performance. This last is a power curve in the case of an offshore wind turbine (OWT) and a marine current turbine (MCT); conversely, it is a power matrix in the case of a wave energy converter (WEC).

Metocean data. The model uses the time-series of the resource data principally to produce the energy estimations of the farm and secondarily to calculate the accessibility of the maintenance vessels respecting their limits and weather windows length. These time-series can be either hindcast or synthetic forecast data, referred to wind, wave and current characteristic parameters. No restrictions exist on the maximum or minimum length of the timestep that separates two consecutive values.

Failure distributions. The occurrence of a failure is a probabilistic event whose likelihood depends on many factors, either intrinsic to the nature of the considered system (or single component) and due to external circumstances. The first somehow reflect the quality of the materials, engineering skills and manufacturing processes adopted to obtain the item; the second represent the effects of environmental factors, loads and usage conditions. The model takes into account both these kinds of mechanism that lead to a failure. In order to allow for the intrinsic aspects of a component its failure rate has to be considered, taken as the frequency of failures over a given period. This value has to be established with data obtained in previous experiences with the same component [17] or, when this is not available, adapted from existing databases [18] or surrogate data using the engineering judgement. A combination of both methods is the most effective choice in order to adapt longstanding databases to a specific context. This is particularly important in the case of marine energy devices, which are generally characterized by limited experience. In addition, this value can be constant or variable depending on the age of the specific component in the considered system and the probabilistic distribution chosen to represent its failure behaviour. A classic example to show this concept is the well-known bathtub curve [19], which gives a clear illustration of the variation of failure rate $\lambda(t)$ over time for a generic component. 


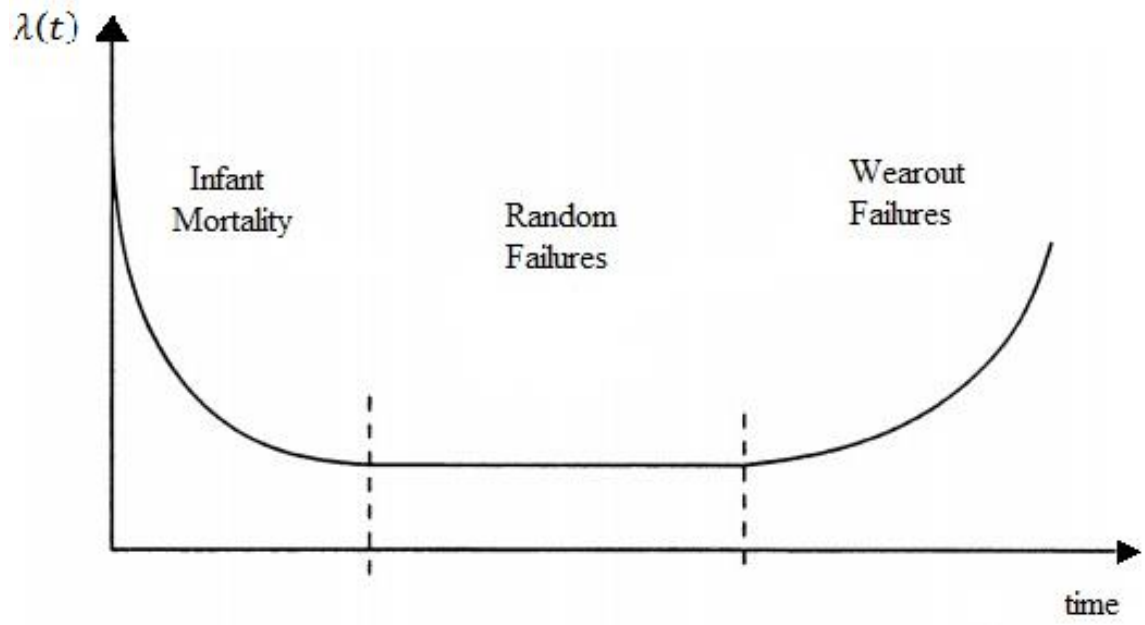

Figure 2. Bathtub curve, representing the generic variation of the failure rate with time.

In reparable systems, the failure rate describes at what rate (in failures/hour) the failures occur within a particular time interval $\left[\mathrm{t}_{1}, \mathrm{t}_{2}\right]$ if no failure has occurred up to $\mathrm{t}_{1}[20]$, and its value is given by the expression:

$$
\lambda(t)=\frac{f(t)}{R(t)}=\frac{f(t)}{1-F(t)}
$$

Where $\mathrm{f}(\mathrm{t})$ is the probability distribution function (pdf) of the failures and $\mathrm{F}(\mathrm{t})$ is the cumulative distribution function (cdf) of the failures. $\mathrm{R}(\mathrm{t})$ is the reliability function of the component and expresses the probability that the item will remain in its operational state (i.e. does not fail) at time $t$ :

$$
R(t)=\int_{t}^{\infty} f(\tau) d \tau=1-F(t)
$$

Thus, the model permits the choice between a constant or variable failure rate and a correspondent failure statistical distribution: exponential for a constant value or Weibull for a variable one.

Exponential failure distribution: $R(t)=e^{-\lambda t}$

Weibull failure distributions: $R(t)=e^{-(t / A)^{B}}$

Where A and B are respectively the scale and shape parameters of the Weibull distribution. Hence, depending on what failure distribution is chosen, different parameters have to be specified among the input data. The failure distributions are then compared against a random number $\left(\mathrm{N}_{\mathrm{R}}\right)$ in the range $[0,1]$ created using the Mersenne Twister algorithm. A failure is simulated when the following condition is satisfied:

$N_{R} \geq e^{-(\lambda(t))^{B}}$

Where $\mathrm{B}=1$ in the case of the Exponential distribution. This method, combined with the Monte Carlo simulation, has been broadly adopted in Reliability analysis [14], [21], [22] . 
Other circumstances, such as weather conditions and the marine environment, can lead to a decrease or increase of the failure rate. Consequently, power rating and environmental stress factors can be considered in order to adjust failure rate values. The model allows for this adjustment using the physics-based model proposed by Davidson [23] to account for environmental influences, embraced in a number of works [16], [24]. It consists of adjusting the failure rate for the different components of the device, collected from a variety of databases, applying appropriate environmental and power rating factors as shown in equation 6.

$\lambda_{C}=\lambda_{B} \cdot \pi_{E} \cdot \pi_{P R}$

Where $\lambda_{C}=$ failure rate of the selected component; $\lambda_{B}=$ base failure rate extracted from database; $\pi_{E}=$ environmental adjustment factor; $\pi_{P R}=$ power rating adjustment factor.

Vessels mobilisation and response time. A number of parameters, among which the fuel cost and the exact time that the vessels take to reach the offshore farm, are established using Mermaid [25], a project planning tool for the risk mitigations on offshore procedures proprietary to Mojo Maritime Ltd. This provides a detailed day-by-day transit time for each day of the year during the simulated period, according to the metocean conditions for that day and all the capabilities of the vessel.

\subsubsection{Constraints}

The restrictions that the dynamic of the system is subjected to are detailed in this section:

Maintenance, fault and consequence categories. Maintenance categories are established for vessels and components in order to allow the maintenance operation only if there is a match between the two categories. These can be used to distinguish between major or minor maintenance interventions, heavy o small components' spares and vessels requirements. Example of these categories can be found in [10] and [26]. This serves to take into account the capabilities of the vessel with respect to size, weight and maintainability of the component. Fault categories on the other hand are used to classify the effects of the failure of a component in terms of severity of the damage, costs and crew needed to solve the problem. Similarly, consequence classes established according to the DNV-GL certification [27], are used in order to measure effects of the failures on production and assets.

Procurement and repair time. These are needed in order to assess the amount of time that each repair will require and, according also to the vessel response time, the total period that the device will eventually remain in downtime as a consequence of a failure.

Spares in stock and replacement costs. The former are used to introduce sequencing rules on the repair process, which can start only if the required part is in stock (otherwise the procurement time has to be added). The latter are used to take the costs of the repairs into account in the economic modelling of the farm.

Fleet information. Type and number of vessels present in the fleet (rented or purchased) are taken into account to respect the sequencing rules during simultaneous downtimes. In this 
way, maintenance operations can take place only if there is a vessel available at that particular moment. If related properties are adequately specified, also helicopters may be considered in the analysis.

Accessibility and weather. Accessibility for maintenance is permitted only if a minimum weather window for that maintenance task is available. This is calculated using the metocean data and considering the operating limits of the vessels. Besides this, only some operations can be performed overnight, depending on properties both of the maintenance vessel and the component to be repaired. Therefore, the model calculates the sunrise and sunset time for every day of the considered period in the selected location. The maintenance overnight is allowed only if the conditions on vessel and failed component are satisfied, otherwise the operation is postponed until there is daylight.

\subsubsection{Mechanisms}

The system (i.e. the offshore farm) evolves with time following appropriate mechanisms:

Corrective maintenance regime. The failures and the consequent downtimes of each device are generated according to the parameters explained above. This constitutes the background for the corrective maintenance operations due to unexpected faults. Every corrective action restores the component to an "as good as new" state, resetting its failure distribution at the value for time $\mathrm{t}=0$.

Planned maintenance and inspections. The model takes into account the period of curtailment due to preventive maintenance operations, scheduled before any possible incidence or casual failure. The associated timesteps are distinguished from those related to corrective maintenance (null production due to an unexpected malfunction of the system). Also this maintenance regime restores the selected component to its initial reliability values.

Components information. A range of information on the components that constitute the device and their disposition (in series or in parallel) in the system is required to start the analysis. For each component, it is necessary to specify whether this is critical (its failure determines the non-functionality) for the subsystem to which it belongs. Analogously, for each subsystem, its criticality for the entire device must be identified. In this way, the downtime of the entire device is determined only when one of its critical subsystems fails, which in turn fails only if one of its critical components fails. Eventual redundant components can be specified too, together with the minimum number necessary to keep the subsystem operative.

Condition-based maintenance is not modelled since one of the main aims of this work is to reduce the reliance on monitoring devices and instruments whose installation, even if able to potentially prevent undesired downtimes, inevitably increase the capital expenditures of the project.

\subsubsection{Outputs}


As a result of the simulations, a series of results is provided. These analyse the different options in terms of reliability, availability and maintainability of the farm, and can be used by the decision maker or operator of the farm to compare different maintenance strategies. These outputs comprehend, but are not limited to:

- Reliability and failure rate distribution of each component/subsystem.

- Power delivered and lost; the latter is distinguished between power lost due to scheduled maintenance tasks or inspections and power lost due to unexpected failures (corrective maintenance).

- Time-based and energy-based availability of every device and the entire farm.

- Number of failures, contribution to unavailability and contribution to total number of failures for each component.

- Risk Priority Number (RPN). This permits the quantification of the importance of a failure by assigning a numeric value generally proportional to its likelihood, severity and detectability. It permits to prioritize risks associated to each component.

- Occurrence/ Severity matrix. This shows the likelihood and consequence of each component's failure.

- Economic model of the offshore farm with costs of the different maintenance operations.

- Monthly and annual analysis on power produced, power lost, revenue and losses.

- Convergence of the results over the simulations and probability exceedance on the same parameters (power produced, power lost, revenue and losses).

- Reliability Block Diagram (RBD) of the system, in order to provide a visual feedback of the introduced information about the device.

A selection of these outputs, according to the results obtained for the case study in this paper, will be analysed and discussed more specifically in section 4 . The criteria that should be used to select one maintenance strategy over the others are the maximisation of the availability of the farm, both in terms of time and, especially, energy produced, and the minimisation of the costs related to the running and management of the farm. At the same time, a compromise has to be reached between the improvement of the maintenance strategies and an increase of the O\&M costs. In fact, a solution that maximizes the availability of the farm may not be the most cost effective if the maintenance efforts to reach that value, then the expenses related to these, are too high. Therefore, a trade-off that allows for an increase in the power production without exceeding in O\&M efforts has to be sought.

A summary of the inputs, constraints, mechanisms and outputs considered within the SADT framework is graphically represented in Figure 3. A flow diagram of the different modules of the tool is illustrated in Figure 4. 


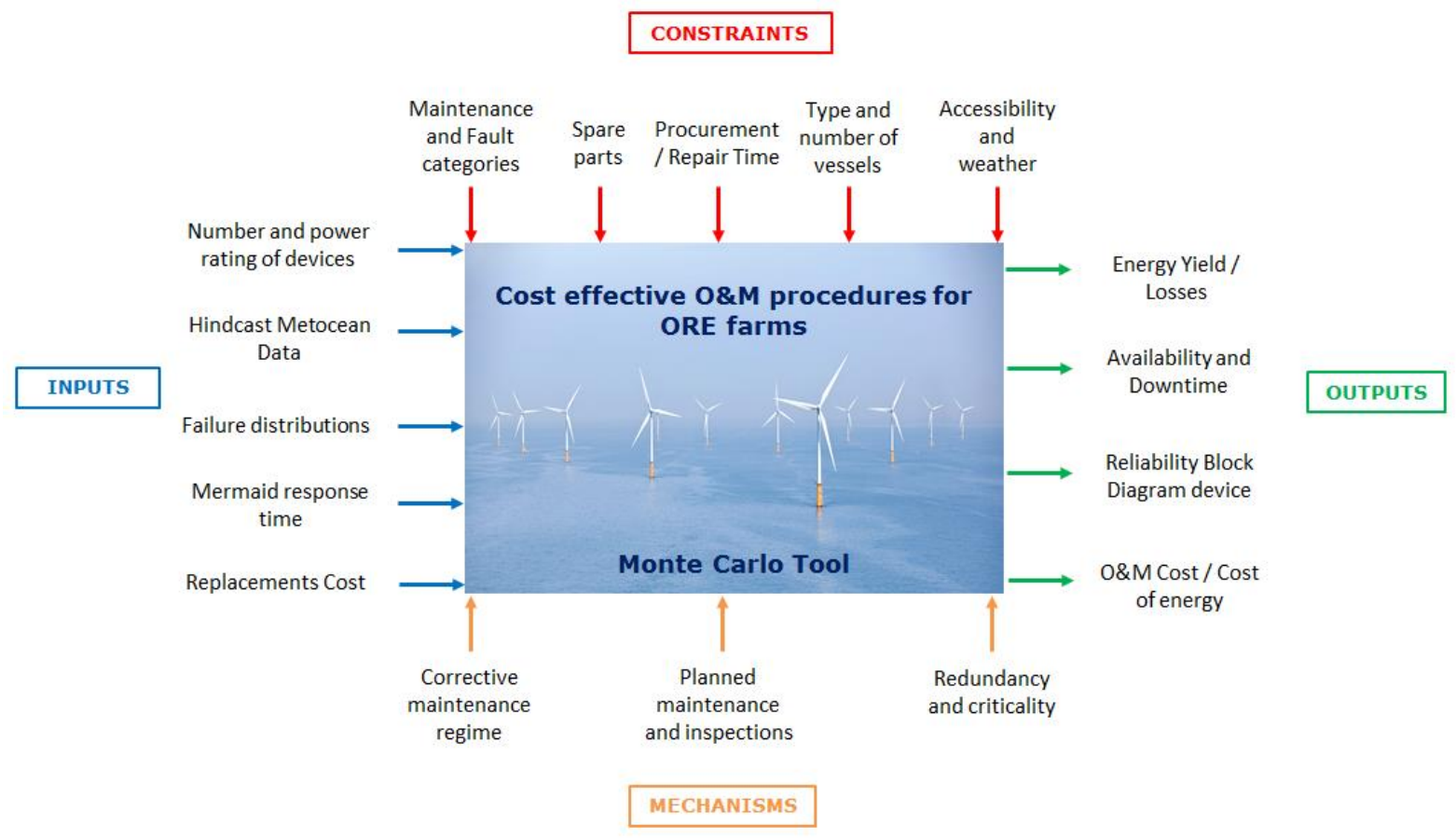

Figure 3. Scheme of the O\&M simulation tool according to the SADT.

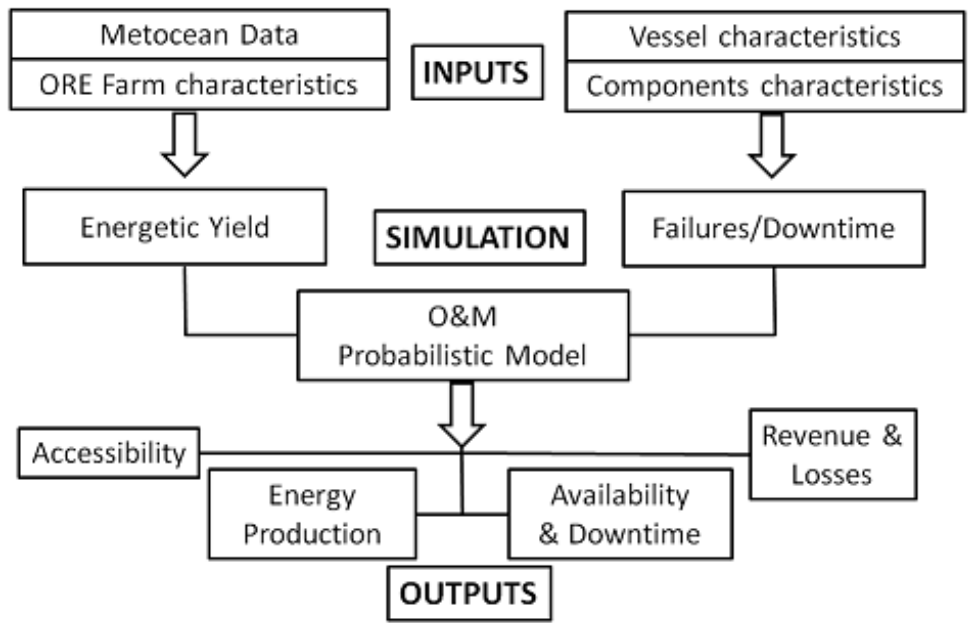

Figure 4. Workflow Diagram of the model [15].

\section{CASE STUDY}

The offshore farm considered for this work is a basic array of tidal stream devices (TSD) constituted of two identical devices. The specifics of the array in terms of the offshore location, source of metocean data, assumed device data and designated maintenance vessels will be described in the following subsections.

\subsection{LOCATION AND METOCEAN DATA}


The site for the positioning of the offshore farm has been chosen for its suitability for tidal energy projects, as demonstrated by the recent Meygen project [28] which aims to deploy the first commercial array of tidal stream turbines in the UK. According to a series of technical and environmental constraints, the identified location is a channel in the Inner Sound of the Pentland Firth, between Stroma Island and the north Scottish mainland, as shown in Figure 5.

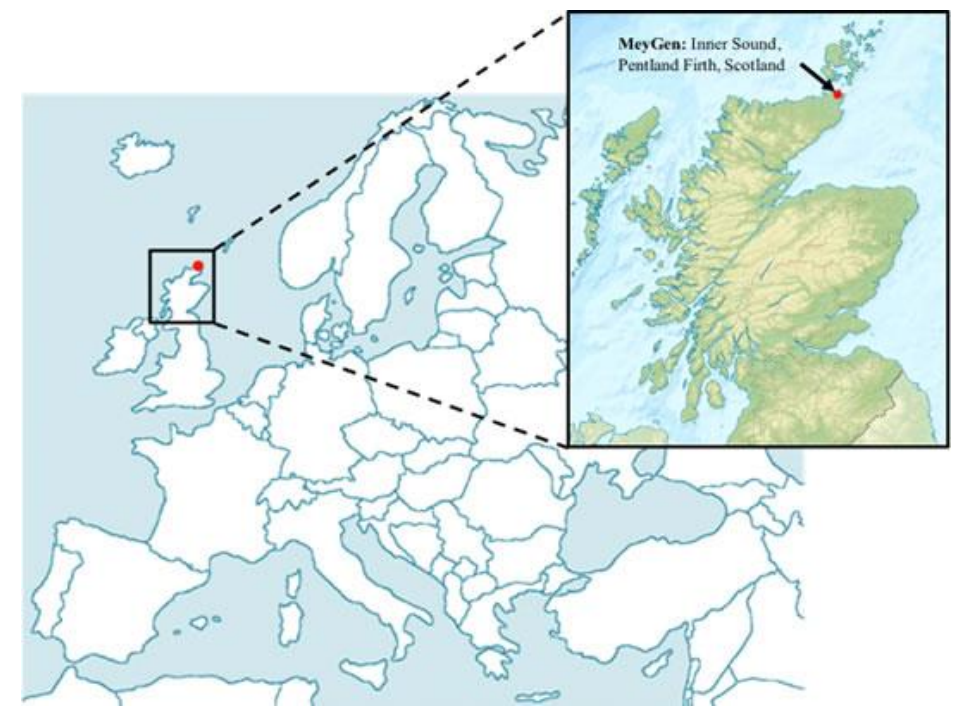

Figure 5. Selected location for the tidal farm. Image from Meygen webpage [28].

The metocean data to characterize this site were retrieved using a range of methods. As regards the wave and wind measurements that are used by the decision support model and Mermaid to establish times and limits of the offshore operations, these were retrieved using the numerical simulation model WAVEWATCH III [29]. As for the tidal current measurements, that are more important because apart from contributing to vessels and operations limits also provide the resource data for the estimation of the energy produced by the devices, these were derived starting from one month of Acoustic Doppler Current Profiler (ADCP). These measurements were then used to reconstruct a complete time series for the considered lifecycle of the farm (10 years) using the MATLAB routine UTide [30].

\subsection{DEVICE}

The TSD considered in this work is a sea-bed fixed single turbine with permanent magnet generator, inspired by the Atlantis Resources (AR) series [31]. More specifically, the fictive device selected for this work is adapted from the AR1000 tidal turbine using the information publicly available in literature. This model is illustrated in the following Figure 6. 


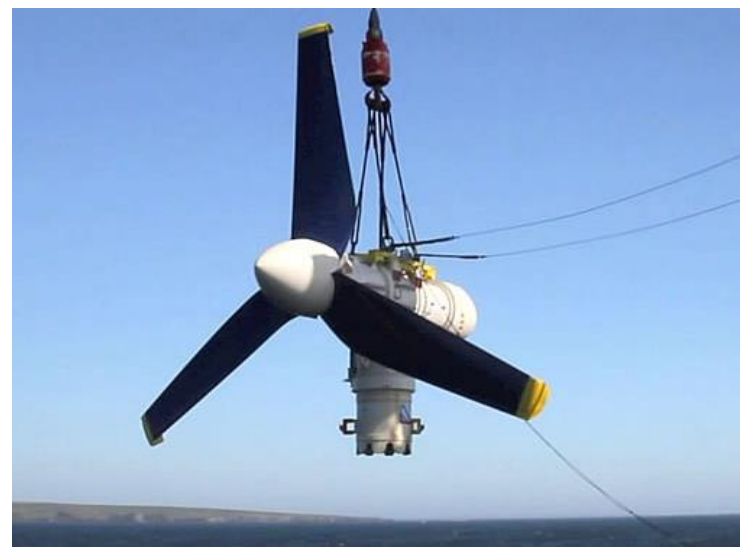

Figure 6. AR1000 horizontal axis tidal turbine. Image from [31].

The information related to the structure and taxonomy of the tidal stream turbines, as well as the related reliability data, were extracted from Delorm, 2014 [32]. The power curve of the turbine has been obtained imposing a cut-in water speed of $1 \mathrm{~m} / \mathrm{s}$, a cut-out water speed of 5 $\mathrm{m} / \mathrm{s}$ and a water velocity corresponding to the output power rated of the turbine (1 MW) of $2.65 \mathrm{~m} / \mathrm{s}$. The power curve between cut-in velocity and rated velocity has been reconstructed using the least squares method. A summary of the TSD's taxonomy, with subsystems and assemblies considered and related data used for the simulation, as well as the RBD and the power curve of the TSD and the water velocities distribution of the location are reported in Appendix A. The offshore farm has been considered as constituted of two identical devices of this kind, positioned in the offshore location at a mutual distance so as to minimize interference and possible wakes in the use of the resource.

\subsection{VESSELS}

The capabilities of the rented or purchased O\&M vessel are a key element in the lifecycle cost model of marine renewables. Two different offshore utility vessels, namely the Dart Fisher offshore supply ship and the HF4 vessel designed by Mojo Maritime, have been compared in the analysis of the various O\&M procedures for the two devices. The first vessel belongs to the category of offshore utility vessels providing specialist crew, cargo transfer and multi-purpose support in the offshore renewables and oil \& gas industries [33]. The second is a vessel capable of operating in extreme offshore environments, designed and projected by Mojo Maritime but not yet manufactured [34]. The relevant specifications of the two vessels are summarised in the following Table 1 . The port selected for all the maintenance operations is the multi-purpose Scrabster harbour [35], located off the north coast of Scotland approximately $25 \mathrm{~km}$ from the offshore location designated for the deployment of the tidal farm.

Table 1. Vessels information used for the analysis.

\begin{tabular}{|lcc|}
\hline & HF4 & $\begin{array}{c}\text { Dart } \\
\text { Fisher }\end{array}$ \\
\hline $\begin{array}{l}\text { Day Rate (£) Waximum Wave Height } \\
\begin{array}{l}\text { Access and Leave Port (m) } \\
\text { Access }\end{array}\end{array}$ & 3.5 & 3 \\
$\begin{array}{l}\text { Maximum Wind Speed to Acceon } \\
\text { and Leave Site (m/s) }\end{array}$ & 15 & 15 \\
\hline
\end{tabular}




\begin{tabular}{|lcc|}
\hline Tidal Current $(\mathrm{m} / \mathrm{s})$ & 5 & 2 \\
Wave Height $(\mathrm{m})$ & 3.5 & 3 \\
Wind Speed $(\mathrm{m} / \mathrm{s})$ & 17 & 15 \\
\hline
\end{tabular}

\section{RESULTS}

In this section the results obtained simulating the lifecycle of the tidal farm are reported in relation to the two O\&M vessels selected for this study. Conclusions on the results obtained together with a number of optimisation possibilities will follow in sections 5 and 6 .

\subsection{RELIABILITY}

This section shows the results obtained in terms of the reliability of the subsystem and single components considered in the taxonomy of the device. The first chart in Figure shows the values of reliability and Mean Time To Failure (MTTF) for each component. The value of reliability in the range $[0,1]$ is calculated at the end of the considered lifetime of the device. This should not be confused with the actual lifetime of the individual component. The MTTF denotes the mean functioning time of the item and represents its life expectancy value [20]. Using the exponential failure distribution its value for each component is given by the inverse of the failure rate, as illustrated in (7):

$M T T F=\int_{0}^{\infty} R(t) d t=\int_{0}^{\infty} e^{-\lambda t}=\frac{1}{\lambda}$

For clarity, a list of the number associated with each considered component of the device and its correspondent Reliability and MTTF is shown in Table 2.

Table 2. List of components characterized [32] and corresponding identification number.

\begin{tabular}{|c|l|c|c|}
\hline$\#$ & Component & Reliability & MTTF $\left[\times \mathbf{1 0}^{\mathbf{6}}\right.$ hours $]$ \\
\hline 1 & Rotor Blades & 0.10 & 0.038 \\
\hline 2 & Hub & 0.08 & 0.035 \\
\hline 3 & Main shaft + bearing, couplings, seal & 0.57 & 0.159 \\
\hline 4 & Gearbox + Lub. \& cooling systems & 0.26 & 0.065 \\
\hline 5 & Hydraulics + Brake System & 0.73 & 0.282 \\
\hline 6 & Rectifier AC-DC & 0.98 & 5.840 \\
\hline 7 & Sync. Generator & 0.06 & 0.032 \\
\hline 8 & Subsea connector & 0.91 & 0.973 \\
\hline 9 & Umbilical (cable + fibre optic) & 0.28 & 0.069 \\
\hline 10 & Nacelle + Turbine controller + corrosion & 0.06 & 0.032 \\
\hline 11 & Structure (foundation + vert. pile + cross-beam) & 0.22 & 0.058 \\
\hline 12 & Electrical System (Converter, Transformer, Switch,..) & 0.003 & 0.015 \\
\hline 13 & Low Voltage DC Electrical Supply & 0.21 & 0.057 \\
\hline 14 & Ancillary System & 0.30 & 0.073 \\
\hline
\end{tabular}



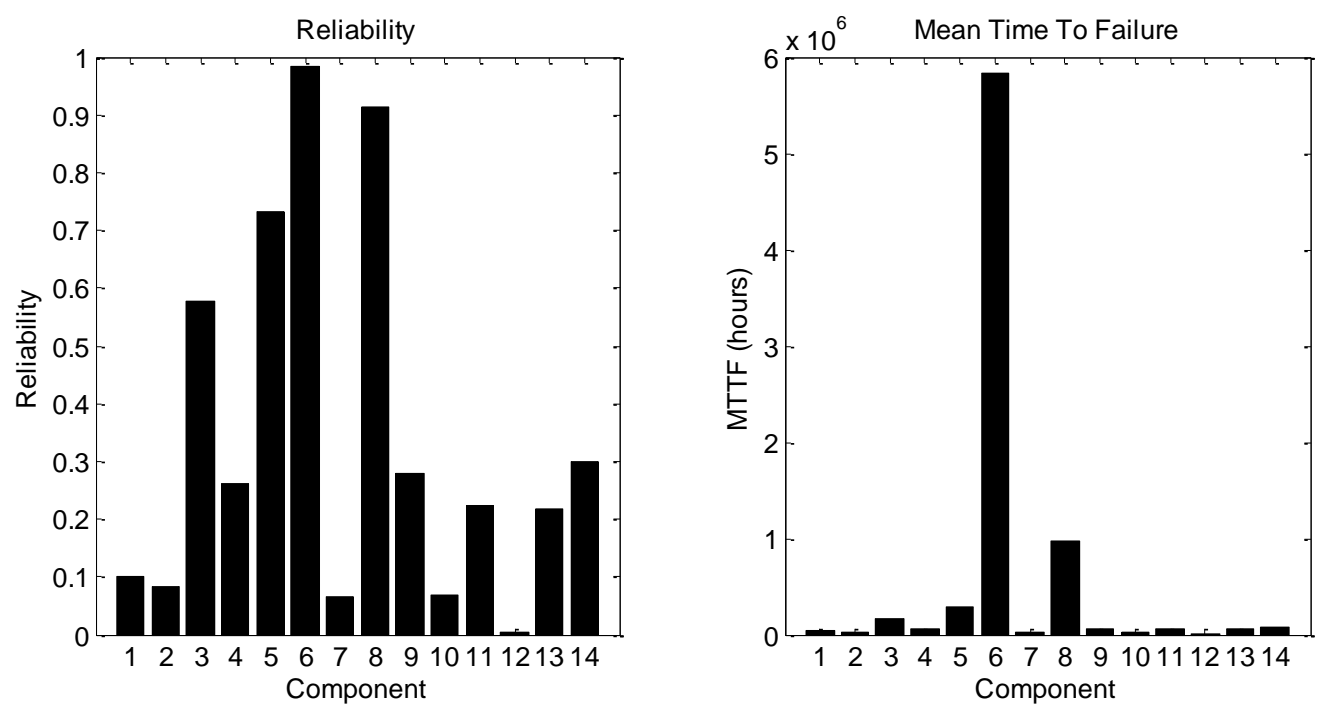

Figure 7. Reliability at the end of the considered lifecycle (10 years) and MTTF for each component of the device.

The reliability of the entire system, calculated considering all the subsystems in series and therefore as the sum of the individual subsystems failure rates, is $2.7163 \times 10^{-4}$ failures/hour. Although a number of items will inevitably be connected in parallel in the real turbine, all subsystems have been considered in series according to the adopted taxonomy and the criticality requirement of each component of the device. In addition, despite some components might experience a limited or partial functioning as a consequence of a failure, here only two states of operation have been considered: working or not working. Under these assumptions, it emerges that the most reliable components are the AC/DC Rectifier, followed by the subsea connector. In contrast the least reliable is the electrical subsystem. This result is observable to some extent also in the graph in Figure 8 showing the total number of failures for each component during the whole lifetime, one per each of the two maintenance vessels employed.
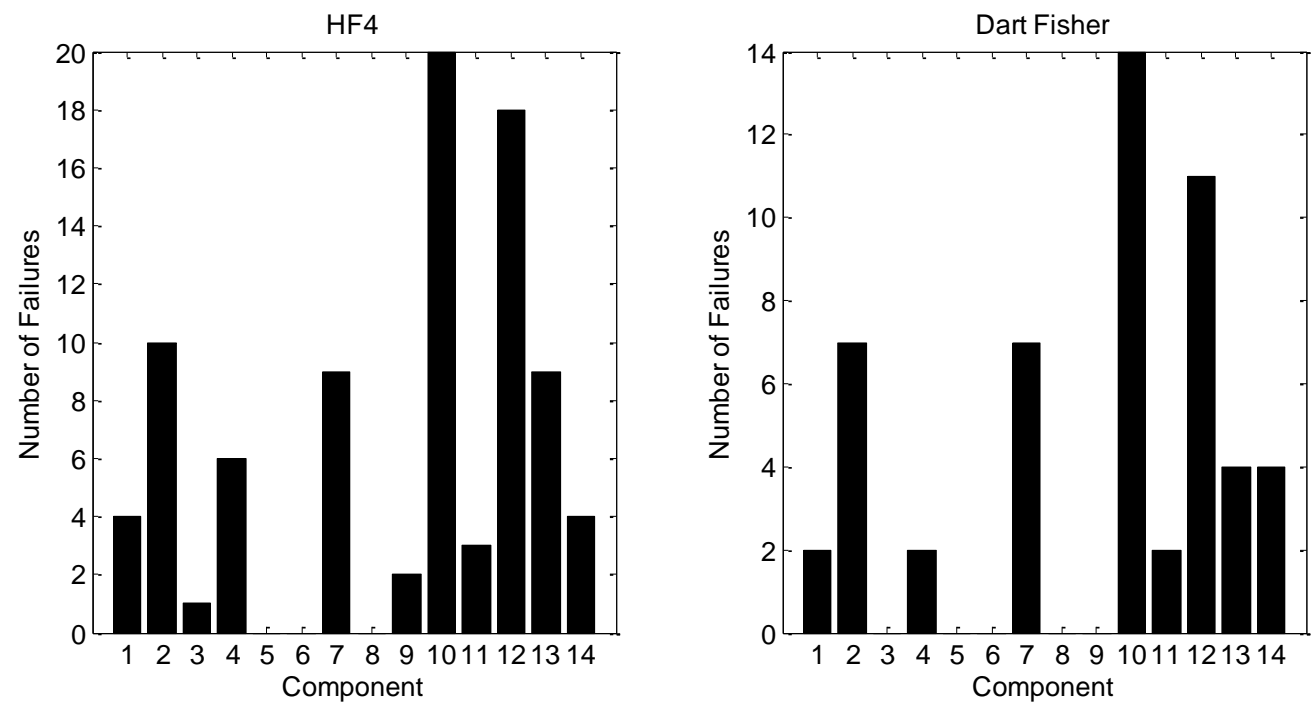

Figure 8. Total number of failures per component. Comparison between the two maintenance vessels. 
More significant considerations on the reliability of each component may be found looking at the next bar chart in Figure . Here, the contribution of each component to the unavailability of the tidal farm is analysed more in detail. In particular, a distinction is made between the percentage contribution to the total number of failures and the total downtime caused. In this way, it is possible to identify those components that fail more often, but especially those that cause a greater downtime. The efforts of the device designers should therefore focus especially on the latter. In this case the component which most contributes both to the total number of failures and the downtime of the devices is the electrical system of the tidal turbine. It can be seen that this is one of the very few components for which the contribution to the total downtime is higher than the contribution to the total number of failures. In fact, the failures of this component alone induce more than the $40 \%$ of the total downtime of the devices. This is due mostly to the high number of items constituting this component, that contribute both to its sensitivity (then failure rate) and to the total amount of time needed to restore it in case of failure (procurement and repair or replacement time). In addition, analogously to most of the other considered components, it is assumed that the turbine nacelle has to be recovered in case of failures, extending the downtime due to weather windows requirements.

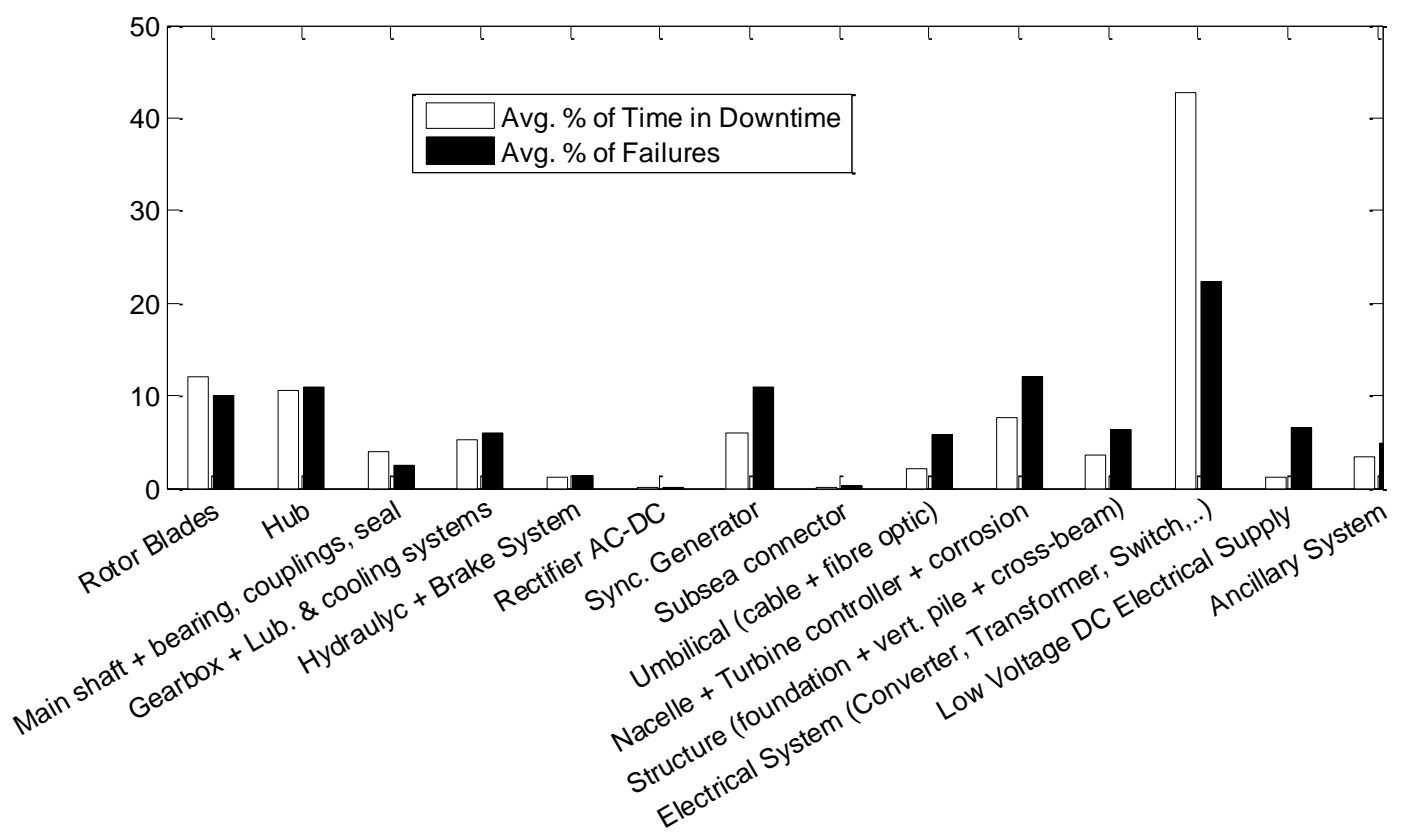

Figure 9. Average contribution of each component of the device to the total number of failures and the total downtime of the farm. In percentage, using the HF4 vessel. 
From these figures it is possible to quantify the importance of each component and prioritize the failures, as showed in Figure 10. In order to do so, it is necessary to rank each failure in terms of a set of parameters. Usually, the Risk Priority Number (RPN) [36] is used for this purpose, which permits the classification of each failure by assigning a number which expresses its Severity (S), Occurrence (O) and Detectability (D), through the expression RPN $=\mathrm{S} \times \mathrm{O} \times \mathrm{D}$.

In order to assign representative values for these quantities, the following construct has been adopted. Starting from the assumption that the risk is usually quantified in terms of likelihood and consequence of a certain event, the likelihood has been compared to the frequency of the undesired event (number of failures) and the consequence to their effect on the power production (downtime). Under these circumstances, from the information in the previous Figure, these values can be obtained associating the occurrence to the average contribution to the total number of failures (the more often a component fails, the higher its contribution to the total number of failures) and the severity to the average contribution to the downtime (the more downtime a failure causes, the higher is the seriousness of the consequences of that failure). Therefore, dividing the two average contributions by 10, it is possible to calculate the occurrence and severity of each failure. The detectability could be assessed considering the likelihood of detection by a control apparatus within a condition-based maintenance regime. However, although it could be possible to estimate this parameter in a separate model, the quantification of the RPN has been restricted to occurrence and severity in order to avoid the introduction of imprecisions in the evaluation of the detectability.

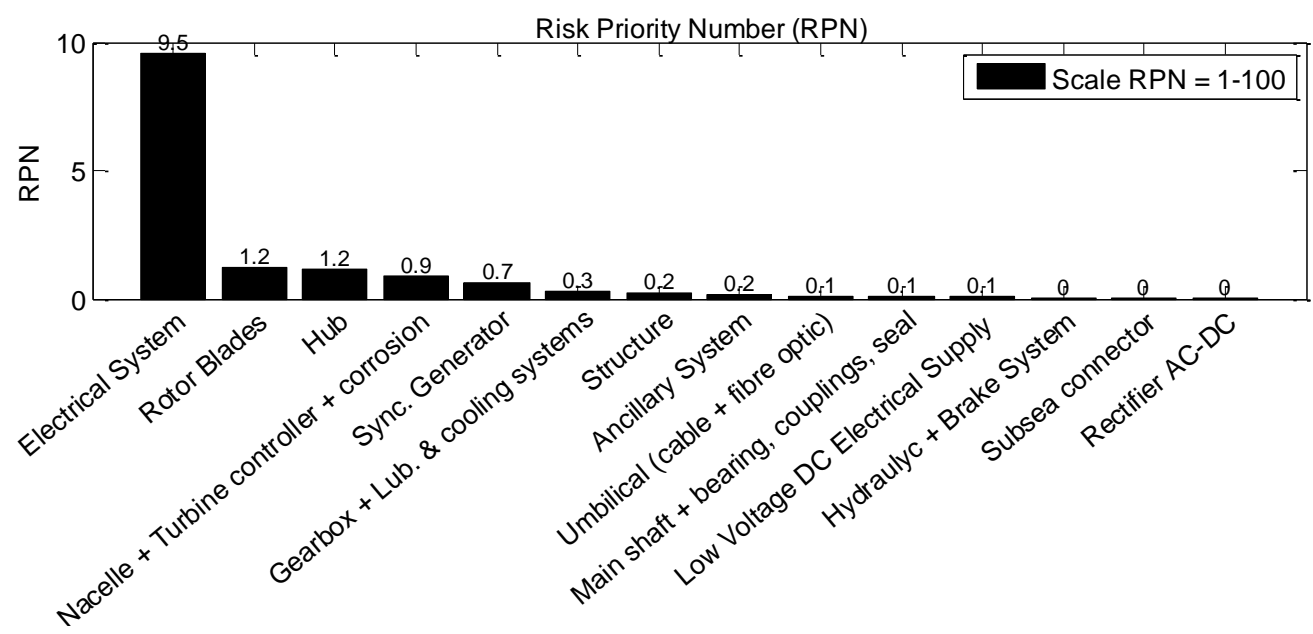

Figure 10. RPN of each component using the HF4.

\subsection{POWER PRODUCTION}

The following charts show the results of the farm in terms of power production, comparing the values obtained using the two different vessels for the O\&M. The ideal electrical energy produced by the 2 devices in the 10 years period resulted to be on average over the simulations $10060 \mathrm{MWh} /$ year. This value has been estimated by applying the modelled power curve to the tidal current velocity time-series derived using UTide. All the unpredicted 
failures, as well as eventual electrical and transportation losses, have been neglected for this calculation. This corresponded to a capacity factor of $57.4 \%$ and 5030 equivalent hours, calculated respectively as:

$$
\begin{gathered}
\text { Capacity Factor }=\frac{\text { Annual energy }}{8760 h \times P_{\text {rated }}} \\
\text { Equivalent Hours }=\frac{\text { Annual energy }}{P_{\text {rated }}}
\end{gathered}
$$

The effects of the unexpected disruptions on the power production and the consequent maintenance operations are shown in terms of energy lost and downtime of the farm in the following charts.
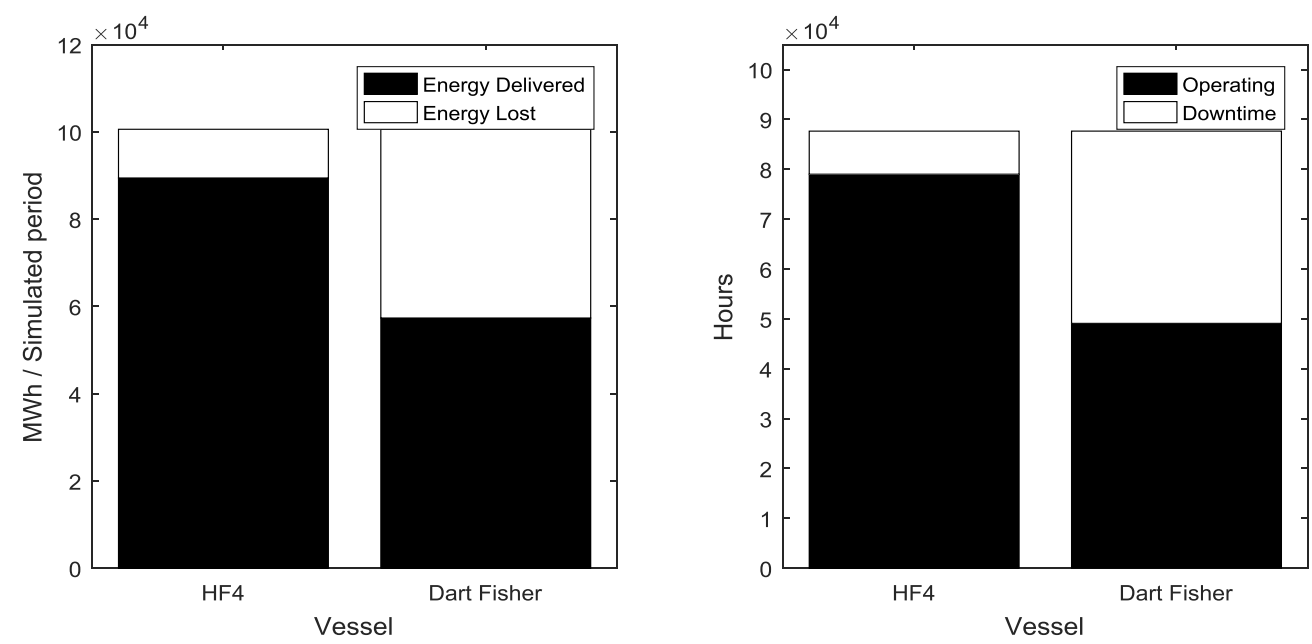

Figure 4. Relationships between energy delivered and energy lost due to failures, and between operating time and downtime, using the two maintenance vessels.

It is clear that the HF4 is preferable for the considered offshore farm in order to reduce the lost production and the downtime due to unforeseen failures. The main reason for this advantage is the capacity of the vessel of operating in high tidal flows up to $5 \mathrm{~m} / \mathrm{s}$. The same results can be analysed more in detail year by year, highlighting the difference in choosing one vessel or the other. 

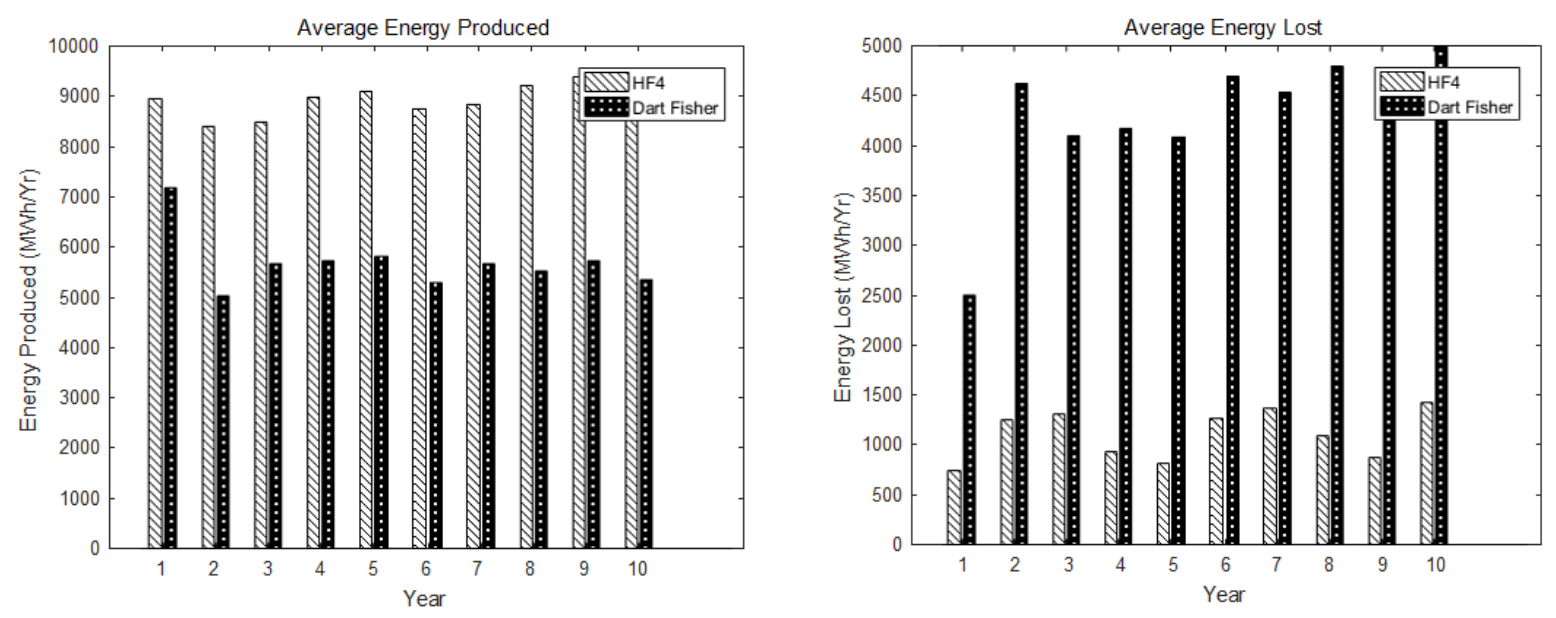

Figure 5. Annual average energy produced and energy lost. Comparison between the two maintenance vessels.

Analysis of these results is available also on a monthly basis. Turning to the availability of the farm, two types can be evaluated, namely time-based and energy-based. The first represents the ratio between the operational time of a device/farm and the total time considered:

$A v_{\text {time- } \text { based }}=\frac{t_{\text {UPTIME }}}{\left(t_{\text {UPTIME }}+t_{\text {DOWNTIME }}\right)}$

Likewise, the energy-based availability expresses the ratio between the real energy produced and the theoretical energy available:

$A v_{\text {energy-based }}=\frac{\text { Actual energy }}{\text { Ideal Energy }}$

Both quantities are useful to evaluate the efficiency of the farm.

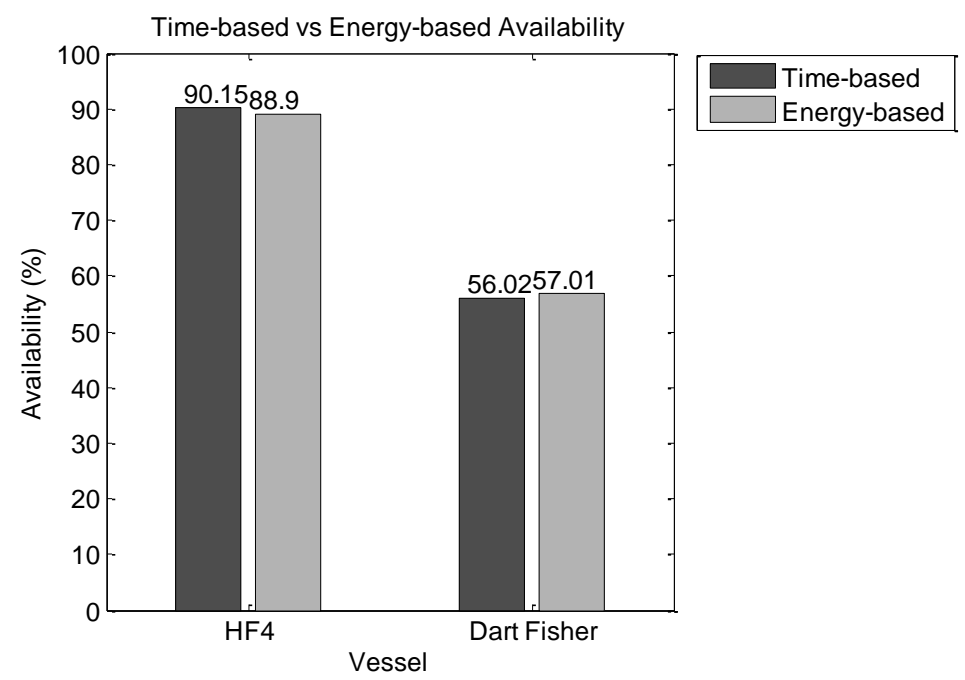

Figure 6. Time-based and energy-based availability for the tidal farm over its lifetime. Comparison between the two maintenance vessels. 
Also this chart points out the higher effectiveness of the HF4 in the maintenance strategy of the devices. Even if the differences between the two vessels are considerable, curiously with the Dart Fisher the energy-based availability, which is more important since revenues are directly proportional to the quantity of energy sold rather than the amount of operating time, is higher than the time-based. This in some way underlines the good practice of making the devices available when the resource is higher, in order to minimize lost production.

\subsection{ECONOMICS}

A further series of results is produced in order to characterize the offshore farm from the economic point of view. This section illustrates the information that project managers can use to take decisions depending on the cost effectiveness of each choice. In order to produce financial estimations, a strike price for the electricity produced by the tidal farm has to be established. For this work, this has been assumed according to the package of measures approved in 2012 by the UK Department of Energy \& Climate Change [37], which determined for the year 2015/16 a price of $305 £$ /MWh for the electricity produced by wave and tidal devices. Applying this price to the values in
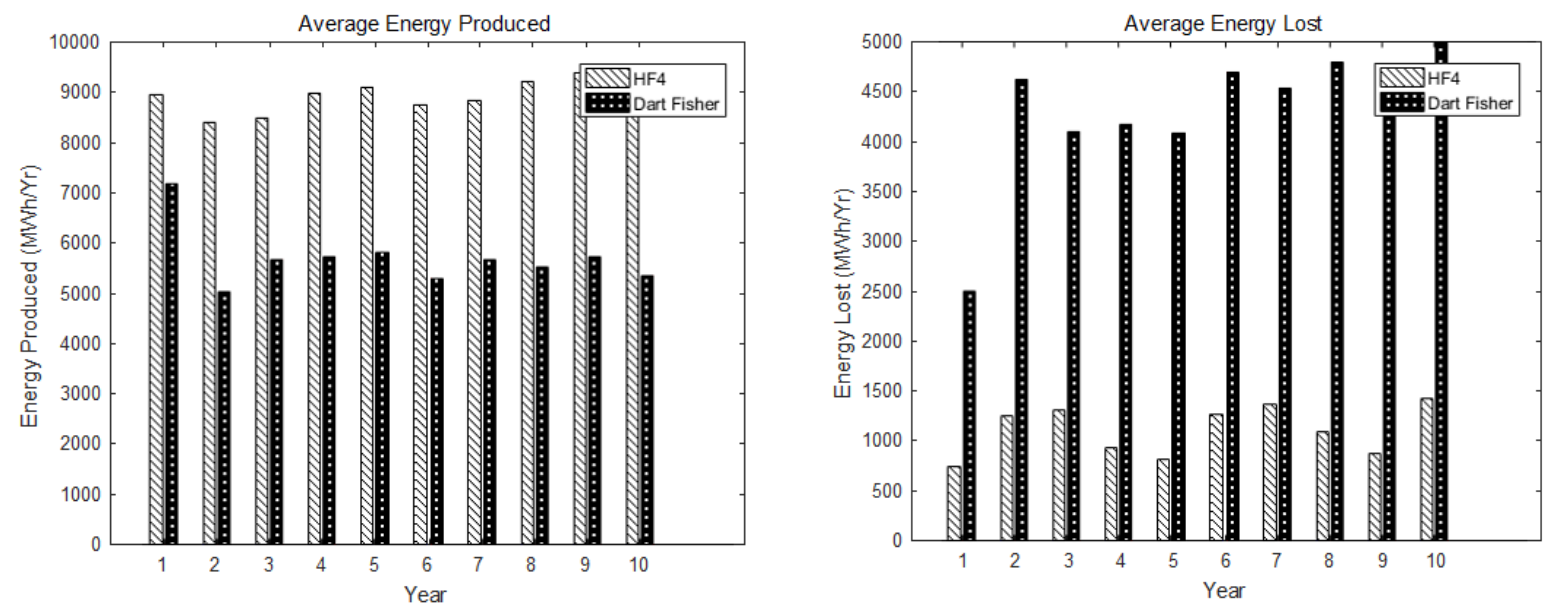

Figure 5. Annual average energy produced and energy lost. Comparison between the two maintenance vessels. , the detail of annual revenue due to the sale of electricity and the financial losses due to unexpected downtimes can be obtained. 

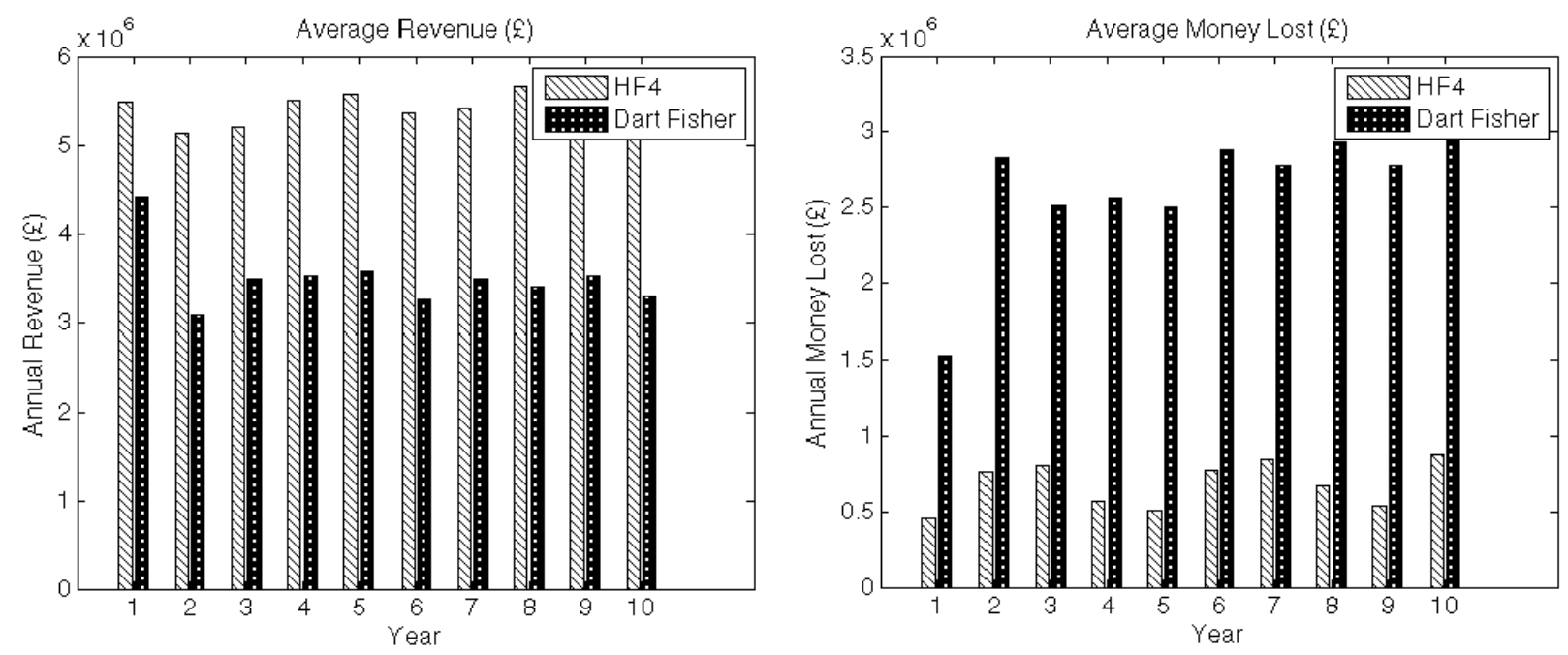

Figure 7. Annual average revenue and money lost. Comparison between the two maintenance vessels.

Since these values have been obtained exploiting a statistical method, the exceeding probabilities associated to these values can also be derived. These figures are particularly useful in the risk assessment of a financial model, since they represent the chances of reaching at least a certain amount of production. These quantities are known as "P values" (Probability values), and indicated as Pxx, where $\mathrm{xx}$ is a number. For instance, P90 denotes the value that is expected to be reached with a probability of $90 \%$.
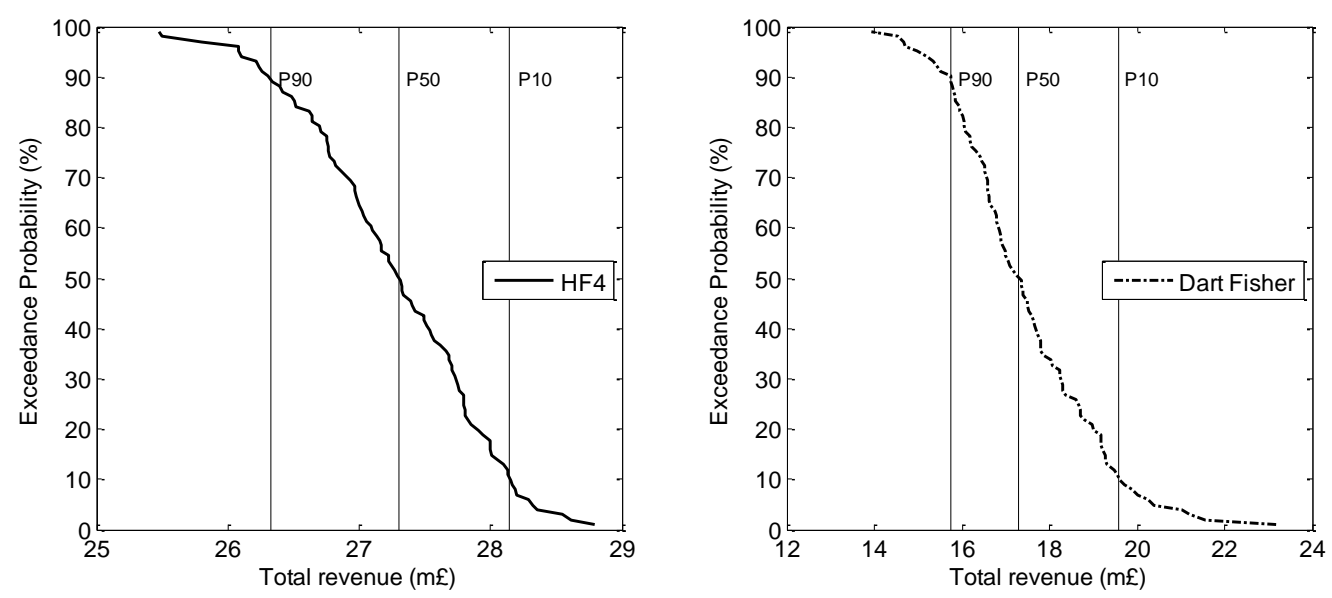

Figure 8. Exceedance probabilities on the total revenue of the farm. Comparison between the two maintenance vessel.

Figure suggests again how the confidence of obtaining major revenue at the end of the lifetime of the farm is much higher using the HF4 vessel. In fact, using the HF4 the P50 of the total gross revenue is $£ 27.28 \mathrm{~m}$, with lost revenue of $£ 3.40 \mathrm{~m}$ in respect to the ideal case of no disruptions, while using the Dart Fisher this is $£ 17.49 \mathrm{~m}$, with estimated lost revenue of $£ 13.19 \mathrm{~m}$. Analogous exceedance probability analysis can be performed on other relevant parameters such as the power delivered (or lost) and the financial losses.

\subsection{SIMULATIONS}


In order to produce reliable results without exceeding with the computational time required for the simulations, a suitable number of runs is sought for the Monte Carlo analysis. Each of these runs simulates the complete lifetime of the tidal farm taking into account all the mechanisms and constraints. Results are then averaged over the total number of simulations in order to obtain the most probable outcome for each parameter. Eventual discrepancies and divergences are quantified at the end of the analysis in order to assess the level of confidence on the results obtained. A first indication of the convergence of the results can be visualised plotting the progressive average of relevant values considered, e.g. the power delivered and power lost.
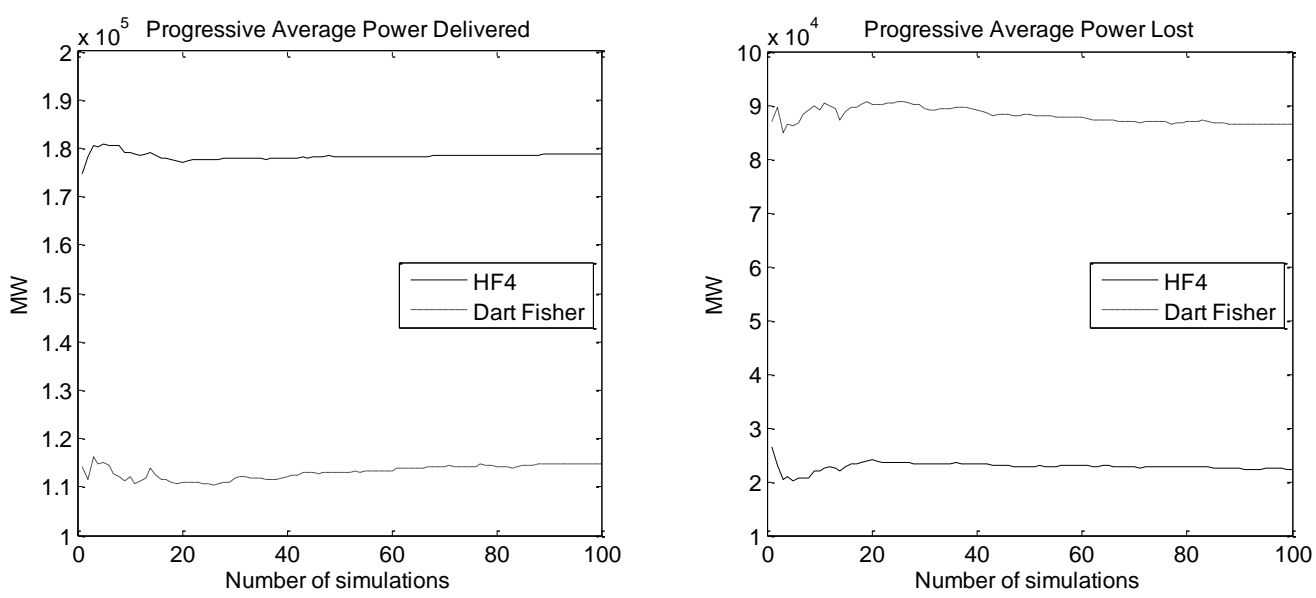

Figure 9. Progressive average through the simulations of the final values of power delivered and lost.

At first glance, the two trends seem quite flat, indicating no or very little variation between one simulation and the next. However, looking at the scale on the y-axis, this shows how even small variations in the graph can correspond to large differences of tens of thousands of MW. For this reason, it is useful to also look at the percentage changes, for example on the power delivered (similar checks can be made also on other parameters).
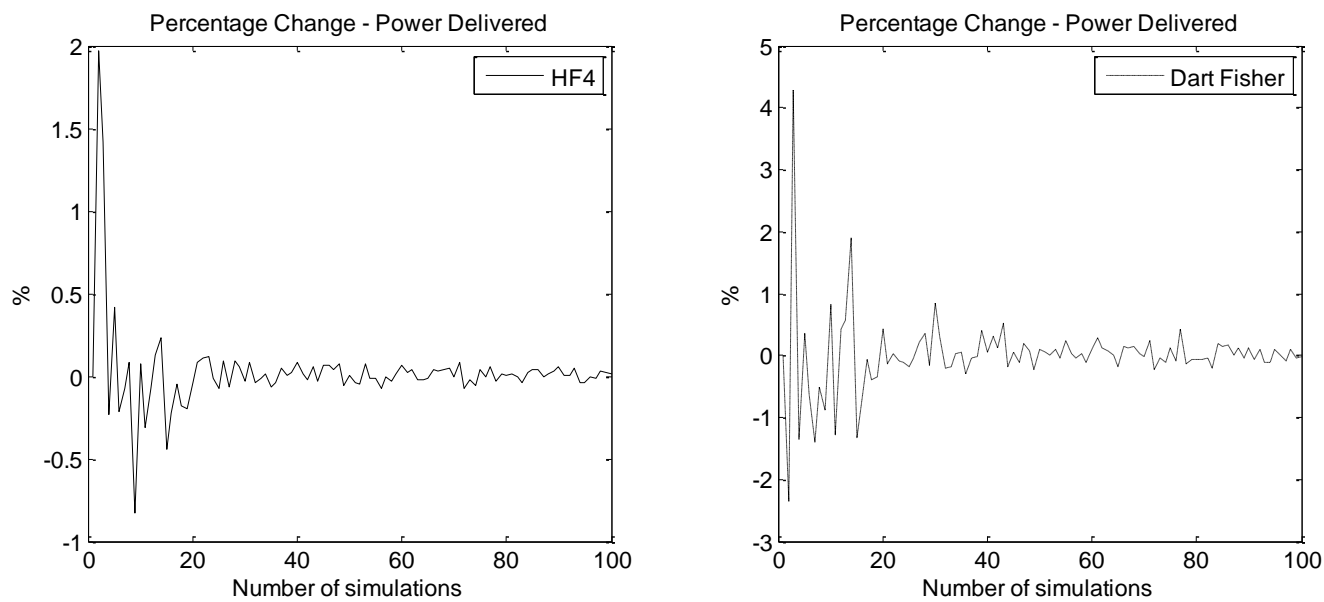

Figure 10. Percentage changes through the simulations of the final value of power delivered. Comparison between the two maintenance vessels. 
Also looking at these figures a satisfactory level of confidence can be attributed to the convergence of the obtained values, suggesting the suitability of 100 simulations in order to obtain meaningful results without exceeding with the computational time required.

\section{FUTURE WORK}

In the absence of the corresponding observable system (an analogous offshore energy farm with known device information, metocean data and O\&M strategy) the validation of each case study is impractical. Nevertheless, repeated simulations and analysis of the outcomes permit to increasingly build confidence on the results obtained. In alternative, a full sensitivity analysis would permit to measure the variance on the results obtained as a consequence of variations in the input set. Despite the setting of a specific framework would be required for such approach, from previous experiences with the implemented tools a number of major factors that have a higher impact on cost and productivity of the farm have been identified. These include, but are not limited to: failure rates, vessels' capabilities, charter strategies, spare parts availability and costs. As a consequence, a number of optimization possibilities arise following the characterization of the offshore farm. Among these, the reduction of the failure rates of the single components due to improvement in the design of the devices, the intensification of scheduled maintenance activities on the most sensitive components, the choice of one or more maintenance vessels which perform better. In any case, all the options would rely on one or more iterative repetitions of the simulated lifetime of the farm, using the information obtained at each cycle and each time varying one or more parameters accordingly, trying to maximize the availability and electrical production of the farms while reducing downtimes and maintenance costs. This procedure and some of the optimization opportunities have been already investigated and discussed in [15]. Each case would require an individual optimization based on the considered assets, and the effective solution for a certain farm with specific size and location may not be valid for a farm with different number of devices and climate. With reference to the model itself, the introduction of new features and options or the inclusion of new inputs, mechanisms and constraints, not only on the modelling of the sub-assemblies of the devices and on the access systems but also on their mutual interaction, will allow the generation of new outcomes. These will permit a more exhaustive characterization of the management procedures of the farm and, as a consequence, more possibilities of optimization of the same. Among these it is worth mentioning more cost entries to better simulate vessels' charter strategies, efficiency factors to take into account transmission and other losses, batch repair thresholds to implement more cost-effective maintenance actions, degradation models to simulate the aging of the components. On the other hand, improvement on the software itself will reduce the simulation time, strengthen the reliability of the method and more in general improve the user experience and facilitate the elaboration of the results.

\section{CONCLUSIONS}


This work has presented the implementation of a reliability-based computational model for the characterization of the O\&M procedures of marine renewables. This tool offers a series of innovative aspects respect to decision support models for the life cycle assessment of power plants. Firstly, its specificity for offshore renewables. Not being a standard tool for the reliability assessment of a generic mechanical or electrical system, it provides exclusively the information useful to owners or operators in the management of an offshore renewable farm. Secondly, its adaptability over different offshore technologies permits to add value to the whole offshore renewables sector providing the possibility to manage different kinds of installations to those operators that owns different assets or, eventually, different technologies in the same offshore farm. In addition, a number of assumptions generally needed in this kind of models have been addressed and where possible, if relevant for the achievement of the information needed, eliminated or reduced. In this context, the integration with the offshore planning software Mermaid in order to remove the assumptions on the modelling of the access systems (vessels, workboats, etc.) is the most significant. A full description of the variables and mechanisms that the model exploits to elaborate the information in support of decision-makers and device developers has been provided. The purpose these data serve is that of quantifying the relative difference between different options and operative choices, as well as evaluate risks associated to each choice. A case study to show the functioning of the toolbox, its modelling possibilities and the information obtainable in order to make decisions on the management of the offshore farm has also been presented. Results show the characterization of the reliability of the devices, identifying the subsystems and components which most affect the correct operation of the turbine. This provides information on what sub-assemblies device designers and engineers should focus on, giving them the opportunity to analyse the effects of improvements in these components. Forecasts on electricity production and availability of the farm are introduced, as well as economic predictions and exceedance probabilities on gross revenue and financial losses. These shows for example what access system is more cost effective to use for the maintenance of the farm. Most of the outcomes in fact can be compared for two or more different maintenance vessels, or even a combination of them. This choice plays a pivotal role in the success of one maintenance strategy over another. Finally considerations on the convergence of the results, due to the statistical nature of the method adopted, are taken into account to assess the confidence in the results obtained and optimise the computational time required.

\section{ACKNOWLEDGEMENTS}

This research has been conducted within the multinational Initial Training Network (ITN) OceaNET, funded under the PEOPLE Programme (Marie Curie Actions) of European Union's FP7. Mojo Maritime have provided access to Mermaid to support, and for integration with, this research.

\section{REFERENCES}

[1] J.J. Nielsen, J.D. Sorensen, On risk-based operation and maintenance of offshore wind turbine components, Reliab. Eng. Syst. Saf. 96 (2011) 218-229. 
doi:10.1016/j.ress.2010.07.007.

[2] M. Shafiee, A. Kolios, A multi-criteria decision model to mitigate the operational risks of offshore wind infrastructures, in: Saf. Reliab. Methodol. Appl., 2015: pp. 539-547.

[3] G. Rinaldi, P.R. Thies, L. Johanning, R.T. Walker, A computational tool for the proactive management of offshore farms, in: 2nd Int. Conf. Offshore Renew. Energy, ASRANet Ltd, Glasgow, UK, 2016: pp. 111-115.

[4] H. Braam, T.S. Obdam, R.P. Van De Pieterman, L.W.M.M. Rademakers, Properties of the O\&M Cost Estimator (OMCE), 2011.

[5] I. Dinwoodie, O. V Endrerud, M. Hofmann, R. Martin, I.B. Sperstad, Reference Cases for Verification of Operation and Maintenance Simulation Models for Offshore Wind Farms, Wind Eng. 39 (2015) 1-14.

[6] M. Hofmann, I. Bakken, NOWIcob - A tool for reducing the maintenance costs of offshore wind farms, 35 (2013) 177-186. doi:10.1016/j.egypro.2013.07.171.

[7] S. Ambühl, M. Kramer, J.D. Sørensen, Risk-based Operation and Maintenance Approach for Wave Energy Converters Taking Weather Forecast Uncertainties into Account, in: Int. Ocean Polar Eng. Conf., 2016: pp. 576-583.

[8] F.D. Mcauliffe, L. Macadré, M.H. Donovan, J. Murphy, K. Lynch, Economic and Reliability Assessment of a Combined Marine Renewable Energy Platform, in: EWTEC 2015, 2015.

[9] R. Martin, I. Lazakis, S. Barbouchi, L. Johanning, Sensitivity analysis of offshore wind farm operation and maintenance cost and availability, Renew. Energy. 85 (2016) 1226-1236. doi:10.1016/j.renene.2015.07.078.

[10] Y. Dalgic, I. Lazakis, O. Turan, Vessel charter rate estimation for offshore wind O\&M activities, in: Int. Marit. Assoc. Mediterr., 2013. http://strathprints.strath.ac.uk/47039/.

[11] Y. Dalgic, I. Lazakis, O. Turan, Investigation of Optimum Crew Transfer Vessel Fleet for Offshore Wind Farm, Wind Eng. 39 (2015) 31-52.

[12] Y. Dalgic, I. Lazakis, I. Dinwoodie, D. Mcmillan, M. Revie, Advanced logistics planning for offshore wind farm operation and maintenance activities, Ocean Eng. 101 (2015) 211-226. doi:10.1016/j.oceaneng.2015.04.040.

[13] M. Hofmann, A Review of Decision Support Models for Offshore Wind Farms with an Emphasis on Operation and Maintenance Strategies, Wind Eng. 35 (2011) 1-16.

[14] D. Alexander, Application of Monte Carlo simulation to system reliability analysis, in: 20th Int. Pump Users Symp., 2003: pp. 91-94.

[15] G. Rinaldi, P.R. Thies, R. Walker, L. Johanning, On the Analysis of a Wave Energy Farm with Focus on Maintenance Operations, J. Mar. Sci. Eng. 4 (2016). doi:10.3390/jmse4030051.

[16] A. Karyotakis, On the Optimisation of Operation and Maintenance Strategies for Offshore Wind Farms, 2011. 
[17] J. Carroll, A. Mcdonald, D. Mcmillan, Failure rate, repair time and unscheduled O\&M cost analysis of offshore wind turbines, Wind Energy. 19 (2015) 1107-1119.

doi:10.1002/we.

[18] D. norske Veritas, OREDA, Offshore Reliability Data Handbook, Høvic, Norway, 2002.

[19] G. Klutke, P.C. Kiessler, M.A. Wortman, A Critical Look at the Bathtub Curve, IEEE Trans. Reliab. 52 (2003) 125-129.

[20] P.R. Thies, Advancing reliability information for Wave Energy Converters, University of Exeter, 2012.

[21] H.S. Bø, Estimation of Reliability by Monte Carlo Simulations, (2014).

[22] M. Takeshi, A Monte Carlo simulation method for system reliability analysis, Nucl. Saf. Simul. 4 (2013) 44-52.

[23] J. Davidson, The reliability of mechanical systems, IMeche Gui, 1994.

[24] F.P. Santos, A.P. Teixeira, C. Guedes Soares, An age-based preventive maintenance for offshore wind turbines, in: Saf. Reliab. Methodol. Appl., 2015: pp. 1147-1155.

[25] http://mojomermaid.com/, (n.d.).

[26] L.W.M.M. Rademakers, H. Braam, O\&M aspects of the $500 \mathrm{MW}$ offshore wind farm at NL7 Baseline Configuration, 2002.

[27] DNV-GL, Certification of tidal turbines and arrays. DNVGL-SE-0163, 2015.

[28] www.meygen.com, (n.d.).

[29] H.L. Tolman, B. Balasubramaniyan, L.D. Burroughs, D. V. Chalikow, Y.Y. Chao, H.S. Chen, V.M. Gerald, Development and Implementation of Wind-Generated Ocean Surface Wave Models at NCEP, Am. Metereological Soc. (2002) 311-333.

[30] D.L. Codiga, Unified tidal analysis and prediction using the UTide Matlab functions, 2011. doi:10.13140/RG.2.1.3761.2008.

[31] http://atlantisresourcesltd.com/, (n.d.).

[32] T.M. Delorm, Tidal stream devices: Reliability prediction models during their conceptual \& development phases, Durham University, 2014.

http://etheses.dur.ac.uk/9482/.

http://www.marinetraffic.com/en/ais/details/ships/shipid:201164/mmsi:235102397/im o:9718040/vessel:DART_FISHER, (n.d.).

[34] http://mojomaritime.com/en/rd/hf4/, (n.d.).

[35] http://www.scrabster.co.uk/, (n.d.).

[36] S. Nune Ravi, P. Bantwal S., Modified approach for prioritization of failures in a system failure mode and effects analysis, Int. J. Qual. Reliab. Manag. 18 (2001) 324- 
336. doi:http://dx.doi.org/10.1108/02656710110383737.

[37] Department of Energy \& Climate Change, Investing in renewable technologies - CfD contract terms and strike prices, 2013.

https://www.gov.uk/government/publications/investing-in-renewable-technologiescfd-contract-terms-and-strike-prices.

\section{APPENDIX A}
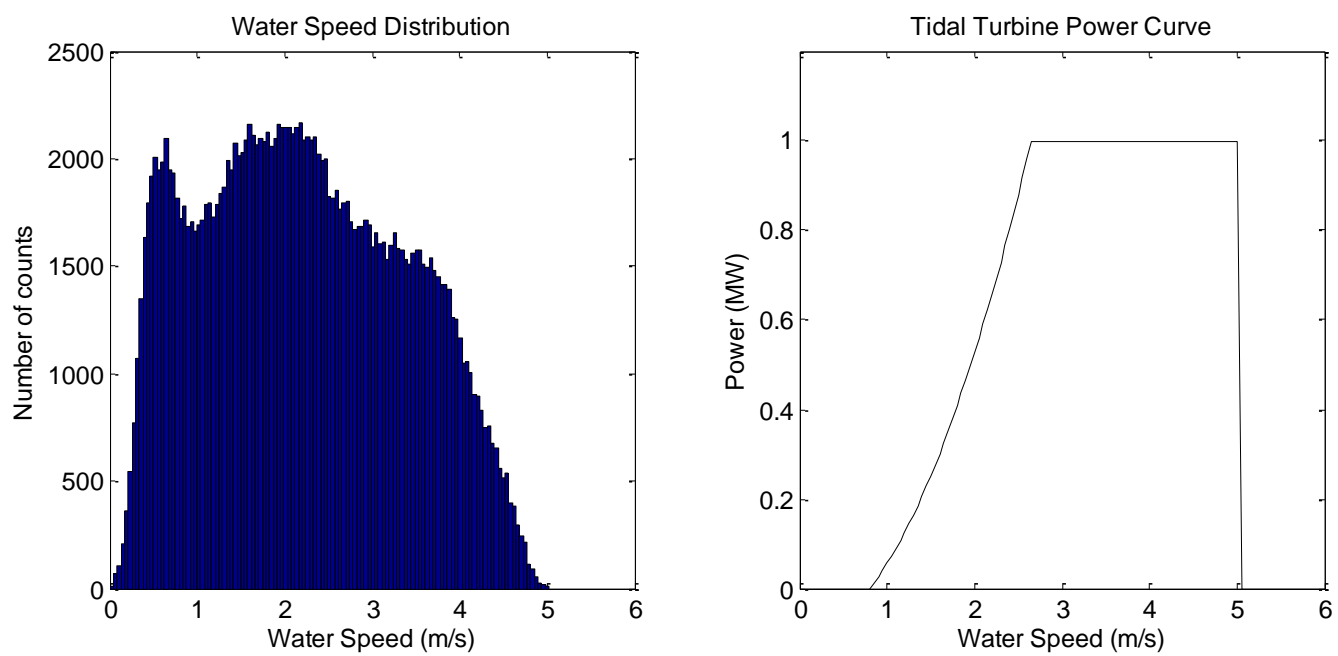

Figure 11. Water velocities distribution of the selected location and Power curve of the considered TSD. 


\begin{tabular}{|c|c|c|c|c|c|c|}
\hline $\begin{array}{l}\text { Sub-assembly / } \\
\text { Component }\end{array}$ & Subsystem & $\begin{array}{c}\text { Annual } \\
\text { Failure rate }\end{array}$ & \begin{tabular}{c} 
Failures \} $\\
{\text { Hour }}$ & $\begin{array}{c}\text { Repairable } / \\
\text { Replaceable } \\
\text { Overnight } \\
\left(\begin{array}{c}1=\text { Yes, } 0= \\
\text { No })\end{array}\right.\end{array}$ & $\begin{array}{c}\text { Maintenance } \\
\text { category }\end{array}$ & $\begin{array}{c}\text { Fault type } \\
\text { category }\end{array}$ \\
\hline Rotor Blades & 1 & 0.23 & $2.62557 \mathrm{E}-05$ & 0 & 2 & 1 \\
\hline Hub & 1 & 0.25 & $2.85388 \mathrm{E}-05$ & 0 & 2 & 1 \\
\hline $\begin{array}{l}\text { Main shaft }+ \text { bearing, } \\
\text { couplings, seal }\end{array}$ & 1 & 0.055 & $6.27854 \mathrm{E}-06$ & 0 & 2 & 5 \\
\hline $\begin{array}{c}\text { Gearbox + Lub. \& } \\
\text { cooling systems }\end{array}$ & 1 & 0.134 & $1.52968 \mathrm{E}-05$ & 0 & 2 & 5 \\
\hline $\begin{array}{c}\text { Hydraulyc + Brake } \\
\text { System }\end{array}$ & 1 & 0.031 & $3.53881 \mathrm{E}-06$ & 0 & 3 & 7 \\
\hline Rectifier AC-DC & 1 & 0.0015 & $1.71233 \mathrm{E}-07$ & 1 & 3 & 8 \\
\hline Sync. Generator & 1 & 0.271 & $3.09361 \mathrm{E}-05$ & 0 & 3 & 5 \\
\hline Subsea connector & 2 & 0.009 & $1.0274 \mathrm{E}-06$ & 1 & 4 & 2 \\
\hline $\begin{array}{l}\text { Umbilical (cable + fibre } \\
\text { optic) }\end{array}$ & 2 & 0.127 & 1.44977E-05 & 1 & 4 & 2 \\
\hline $\begin{array}{c}\text { Nacelle + Turbine } \\
\text { controller }+ \text { corrosion }\end{array}$ & 3 & 0.269 & $3.07078 \mathrm{E}-05$ & 0 & 2 & 1 \\
\hline $\begin{array}{c}\text { Structure (foundation + } \\
\text { vert. pile + cross-beam) }\end{array}$ & 4 & 0.15 & $1.71233 \mathrm{E}-05$ & 0 & 2 & 1 \\
\hline $\begin{array}{c}\text { Electrical System } \\
\text { (Converter, Transformer, } \\
\text { Switch,..) } \\
\end{array}$ & 5 & 0.58 & $6.621 \mathrm{E}-05$ & 0 & 3 & 7 \\
\hline $\begin{array}{l}\text { Low Voltage DC } \\
\text { Electrical Supply }\end{array}$ & 6 & 0.152 & $1.73516 \mathrm{E}-05$ & 1 & 4 & 8 \\
\hline Ancillary System & 7 & 0.12 & $1.36986 \mathrm{E}-05$ & 1 & 3 & 10 \\
\hline
\end{tabular}
\end{tabular}

Figure 12. Components of the device and related information used for the simulation.

As specified in section 3.2, the information related to the structure and taxonomy of the tidal stream turbines, as well as the related reliability data, were extracted from Delorm, 2014 [32].

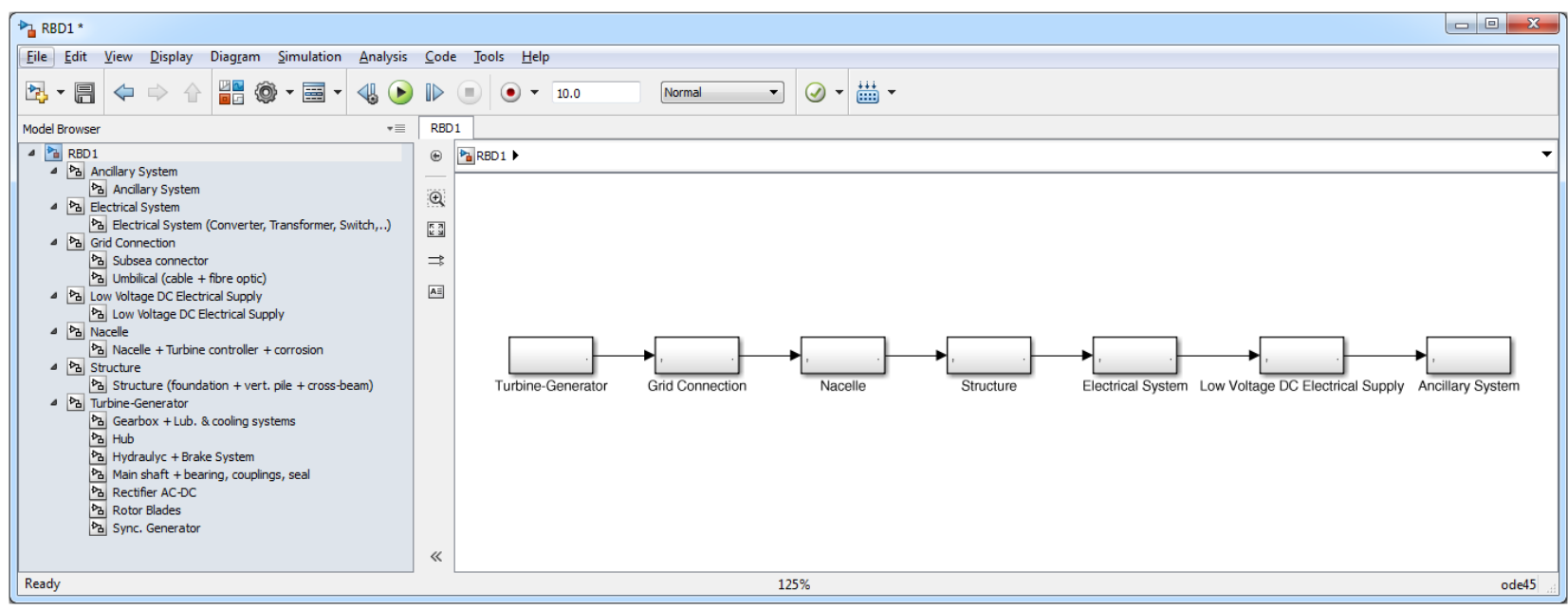

Figure 20. Reliability Block Diagram (RBD) in Simulink ${ }^{\circledR}$ showing the considered subsystems of the device. 
